*Advogada OAB/PB. Mestranda em Direito Econômico pela Universidade Federal da Paraíba - UFPB. Graduada em Direito pelo Centro Universitário de João Pessoa - UNIPE.

E-mail: anna.k.brisola@gmail. com

**Advogado. Pós-graduando em Direito Civil e Processo Civil pela ESA/PB. Bacharel em Direito pelo Centro Universitário de João Pessoa - UNIPE.

E-mail: j.alves18@outlook.com

***Pós-Doutorado na Università degli Studi di Firenze, UNIFI. Doutorado em Direito do pela Pontifícia Universidade Católica de São Paulo, PUC-SP. Professora colaboradora na Universidade Federal da Paraíba, UFPB.

E-mail: herthaurquiza@gmail. com

\section{A NEUTRALIDADE TRIBUTÁRIA E A RESPONSABILIDADE \\ SOCIAL DAS EMPRESAS COMO CONTRIBUTOS PARA O COMBATE ÀS INFRAÇÕES À ORDEM ECONÔMICA}

\section{Tax Neutrality And Corporate Social Responsibility As Contributions To Combat Violations Of The ECONOMIC ORDER}

Anna Karla da Silva Brisola*
José da Silva Alves Júnior**
Hertha Urquiza Baracho***

Como citar: BRISOLA, Anna Karla da Silva; ALVES JUNIOR, José da Silva; BARACHO, Hertha Urquiza. A neutralidade tributária e a responsabilidade social das empresas como contributos para o combate às infrações à ordem econômica. Revista do Direito Público, Londrina, v. 16, n. 3, p. 44-59, dez. 2021. DOI: $10.5433 / 24157-108104-1.2021 v 16 n 3 p .44$. ISSN: $1980-511 X$

Resumo: A ordem econômica e financeira na Constituição Federal de 1988 tem como um dos princípios basilares a livre concorrência. Contudo, apesar das diversas garantias no texto constitucional e na legislação infraconstitucional, o mercado ainda enfrenta diversas condutas nocivas. Por tais razões, este artigo tem por objetivo de pesquisa a defesa da concorrência. Partindo dessa perspectiva, foi necessário fazer uma análise da ordem econômica e da atuação do Estado no domínio econômico, assim como observar a construção histórica da defesa da concorrência nas Constituições brasileiras. Como as infrações econômicas são uma realidade atual, foi preciso demonstrá-las junto com a atuação do Conselho Administrativo de Defesa Econômica (CADE). Por último, mas não menos imperioso, justificou-se a neutralidade tributária e a responsabilidade social das empresas como contributos na defesa da concorrência. Conclui-se que, a neutralidade tributária constitui um mecanismo de concretização da justiça social e de equilíbrio do mercado, enquanto a responsabilidade social auxilia a defesa da concorrência em razão de exigir das empresas uma postura ética. Desta forma, este artigo empregou como metodologia o método do positivismo-lógico, através de uma abordagem indutiva e da pesquisa bibliográfica.

Palavras-chave: Direito Econômico; Defesa da Concorrência; Neutralidade Tributária; Responsabilidade Social das Empresas.

Abstract: The economic and financial order in the Federal Constitution of 1988 has as one of the basic principles free 
competition. However, despite the various guarantees in the constitutional text and in infraconstitutional legislation, the market is still facing various harmful practices. For these reasons, this article aims to research the defense of competition. From this perspective, it was necessary to make an analysis of the economic order and the performance of the State in the economic domain, as well as to observe the historical construction of the defense of competition in the Brazilian Constitutions. As economic infractions are a current reality, it was necessary to demonstrate them along with the actions of the Administrative Council of Economic Defense (CADE). Last but not least, tax neutrality and corporate social responsibility were justified as contributions in the defense of competition. The basis for such results was based on bibliographical research and the method of inductive-deductive approach. It is concluded that tax neutrality is a mechanism for achieving social justice and market equilibrium, while social responsibility helps to defend competition by demanding from companies an ethical stance.

Keywords: Economic Law. Defense of Competition. Tax Neutrality. Corporate Social Responsibility. 


\section{INTRODUÇÃO}

A Constituição Federal é a base do hodierno modelo de sistema econômico brasileiro. Consoante a doutrina majoritária, o Texto Político de 1988 instaurou, no título VII - Da Ordem Econômica e Financeira, do art. 170 a 192, um sistema econômico capitalista fundado na propriedade privada cujo capital é fator preeminente dos sistemas de produção.

Todavia, malgrado seu cunho capitalista, o Estado Brasileiro - de carácter Regulador, preocupou-se com intensa participação estatal para salvaguardar proteção social e efetivar políticas públicas com o fim de assegurar a todos uma existência digna, conforme os ditames da justiça social. Ocorre que tais mecanismos não têm se mostrado suficientes para proteger o mercado das práticas abusivas e garantir uma justa concorrência, além de que, tais práticas impedem a concretização dos ditames constitucionais por parte do Estado.

Nesse diapasão, tem-se como problemática: como a neutralidade tributária e a responsabilidade social das empresas podem colaborar no combate às infrações à ordem econômica?

O presente artigo, fundamentado na revisão crítica da literatura, visa apontar as principais normas que salvaguardam a ordem econômica brasileira, bem como a atuação do Estado no domínio econômico para reprimir infrações à ordem econômica.

Preliminarmente, teceremos a linha histórica das Constituições brasileiras com o intuito de verificarmos, a partir do momento histórico-social em que foram produzidas, quais Constituições disciplinaram sobre o tema deste estudo. Ademais, abordaremos a sistemática Constitucional trazendo à discussão o entendimento doutrinário sobre os princípios da ordem econômica brasileira e sobre quais situações o Estado intervém para salvaguardar o bem-estar coletivo.

Diante do exposto, pretende-se examinar a neutralidade tributária e a responsabilidade social das empresas como instrumentos de uma ordem econômica pautada numa economia justa e participativa.

Para efetivar esse desígnio, utilizou-se o método positivismo lógico, com natureza predominantemente qualitativa, baseado em materiais bibliográficos e documentos legais.

\section{DEFESA DA CONCORRÊNCIA NAS CONSTITUIÇÕES BRASILEIRAS}

As Constituições representam o momento histórico e social em que são organizadas. Ao realizarmos uma análise no histórico das Constituições brasileiras identificaremos, a partir de uma análise do momento político-social em que foram produzidos, quais movimentos influenciaram na sistematização dos Textos Constitucionais pátrio. O organismo Constitucional é, destarte, produto interno da sociedade.

Partindo-se desta premissa, no Brasil, a Carta Política de 1824 - outorgada por D. Pedro I e que concentrava todo o poder nas mãos do imperador -, não versou sobre um sistema econômico 
ao passo que à época os textos constitucionais traduziam, apenas, as normas de organização do Estado. Todavia, a Constituição da Monarquia, conforme Figueiredo (2014, p. 91) se destacou como um dos primeiros textos constitucionais a versar sobre direitos fundamentais.

Consequentemente, em 1891, com o advento da Proclamação da República, promulgouse a Constituição da República dos Estados Unidos do Brasil. Ademais, não diferente da Carta Imperial, o Texto Constitucional vigente não tratou da matéria econômica, sendo, assim, criticada pela omissão. Contudo, estabeleceu as primeiras medidas intervencionistas do Estado.

Em terceiro lugar, em 16 de julho de 1934, promulgou-se a segunda Constituição da República. O Texto Constitucional supracitado foi a primeiro a acautelar uma ordem econômica e social influenciada pelas Constituições do México (1917) e a Constituição de Weimar (1919) que consubstanciaram um modelo de Estado Social. Estabeleceu um regime intervencionista permitindo ao Estado proteger os interesses coletivos em detrimento dos individuais.

Além disso, a Constituição de 1934 conforme seu preâmbulo constitucional tinha por escopo "organizar um Estado democrático, que assegure à Nação, a unidade, a liberdade, a justiça e o bem-estar social e econômico".

Por conseguinte, em 1937, influenciada pela Constituição da Polônia, que se baseava nos movimentos nazistas e fascistas, outorgou-se a quarta Constituição dos Estados Unidos do Brasil. Igualmente, a ordem econômica foi disciplinada sendo tratada, assim, em capítulo próprio.

Ocorre que, não diferente da Constituição que a antecedeu, a Carta Política de 1937 não trouxe inovações quanto ao tema, apenas ratificou o Estado como ente intervencionista e regulador.

A Constituição de 1946, por sua vez, resultante de uma Assembleia Nacional Constituinte, estabeleceu múltiplas modificações em relação à Carta Política de 1937. O enfoque, então, fundamenta-se nos princípios da justiça social com foco na liberdade de inciativa e valorização da dignidade do labor humano.

Mais adiante, em 1967, sob o regime militar, instaura-se um novo Texto Constitucional ratificando o modelo intervencionista de Estado, pautado na ideia nacionalista, e direcionado ao desenvolvimento e segurança nacional. Reporta-se que o desenvolvimento econômico, juntamente com a justiça social - oriundo da Emenda Constitucional de 1969 - reafirma as conquistas jurídicas pretéritas.

Por fim, o Constituinte de 1988 instaurou um título próprio acerca da Ordem Econômica e Financeira fundamentando, em seu art. 170, que a ordem economia, fundada na valorização do trabalho humano e na livre inciativa, tem por fim assegurar a todos uma existência digna, com base nos ditames da justiça social.

\section{A ORDEM ECONÔMICA BRASILEIRA E ATUAÇÃO DO ESTADO NO DOMÍNIO ECONÔMICO}

O alicerce da ordem econômica brasileira, atualmente, estrutura-se na Constituição 
brasileira. Todavia, sua dimensão é produto de uma construção social que paulatinamente adquiriu extensão jurídica e firmou-se a partir da sistematização do tema em Constituições do mundo inteiro.

O Estado é uma "ordem jurídica soberana que tem por fim o bem comum de um povo situado em determinado território" (DALLARI, 1995, p. 101). Ademais, seu escopo social é caractere do Estado Moderno que surgiu como consequência das lutas contra o Estado Absoluto, se transpondo para afirmação dos direitos naturais da pessoa humana.

Destarte, com o processo de transformação do Estado, resultante de movimentos políticosociais, instaurou-se um processo de proteção social e repartição de renda, positivada nos Textos Constitucionais, no rol dos denominados direitos sociais. Figueiredo (2014, p. 68) preleciona:

Após a efetivação dos valores políticos idealizados como basilares do novo modelo de Estado, ao qual se denominou Liberal, ante o regime de garantia de liberdades individuais e proteção ao domínio privado, mister se fez garantir proteção aos segmentos sociais marginalizados, minoritários e, consequentemente, excluídos do processo de produção e repartição de riquezas.

Consequentemente, com o escopo de salvaguardar e efetuar políticas públicas fundadas no bem-estar social, o Estado, que existe para a consecução do bem comum, passou a intervir na ordem econômica. Hodiernamente, com a Constituição Federal de 1988, o Estado brasileiro - de caractere regulador - afastou o modelo absoluto de intervenção na economia atuando em situações que demonstrem imperativos à segurança nacional, de relevante interesse coletivo, além do monopólio constitucional, disciplinados nos art. 173 a 177 da CRFB/88.

Ademais, ordem econômica diz respeito ao conjunto de regras e princípios estabelecidos na Lei Maior que orientará a intervenção do Estado no domínio econômico. Segundo José Afonso da Silva (2001, p. 771), “a ordem econômica consiste na racionalização jurídica da vida econômica, com o fim de se garantir o desenvolvimento sustentável da Nação".

Tavares (2006, p. 81), por sua vez, define como “a expressão de um certo arranjo econômico, dentro de um específico sistema econômico, preordenado juridicamente. É a sua estrutura ordenadora, composta por um conjunto de elementos que confronta um sistema econômico".

Além disso, a doutrina majoritária reconhece que a Constituição brasileira adotou o sistema econômico capitalista fundado na propriedade privada e cujo capital é fator preeminente dos sistemas de produção.

De tal leitura depreende-se a riqueza do dispositivo, que traz normas relativas ao fundamento e aos princípios da ordem econômica, além de servir como parâmetro para sua compreensão (FIQUEIREDO, 2014, p. 93). O supracitado artigo salvaguarda: “Art. 170. A ordem econômica, fundada na valorização do trabalho humano e na livre iniciativa, tem por fim assegurar a todos existência digna, conforme os ditames da justiça social, observados os seguintes princípios [...]".

A valorização do trabalho, disciplinado no art. 170, caput, constitui fundamento da República Federativa do Brasil, conforme o art. $1^{\circ}$, inc. IV da CF/88. Desse modo, entende-se que a valorização do trabalho representa um princípio do Estado brasileiro. Trata-se de uma forma de 
garantir ao homem brasileiro uma vida digna, pautada na valorização de seu labor, podendo ser operacionalizada na efetivação de direitos sociais do trabalhador como o salário mínimo, férias, fundo de garantia por tempo de serviço, descanso remunerado etc.

A livre iniciativa integra o segundo fundamento da ordem econômica brasileira. Desde logo se reconhece a ideia de liberdade de empresa, de modo que veda ao Estado restringir o desempenho da atividade econômica, estabelecendo exceções para esta regra. Tavares (2006, p.83) defende que o fundamento da livre iniciativa possui uma conotação normativa positivada, que permite liberdade a qualquer pessoa, e um viés negativo, ao ponto que estabelece a não intervenção estatal.

Figueiredo (2014, p. 95) afirma que a noção de livre iniciativa expressa a liberdade de entrar, permanecer e sair do mercado sem interferências externas. Além disso, o parágrafo único do art. 170 materializa a livre iniciativa ao assegurar o livre exercício de qualquer atividade econômica, independentemente de autorização de órgãos públicos, salvo nos casos previstos em lei. Ademais, faz-se mister elucidar que tais fundamentos têm por escopo assegurar a todos uma existência digna, conforme os ditames da justiça social.

Deve-se sublinhar, ainda, que a ordem econômica, fundamentada na valorização do trabalho e na livre iniciativa, cujo escopo destina-se à existência digna apresenta, em nove incisos do art. 170 da CRFB, princípios basilares que servem de parâmetros para o efetivo funcionamento da ordem econômica.

O primeiro destes princípios diz respeito à soberania nacional, que representa similarmente um fundamento da República Federativa do Brasil (art. $1^{\circ}$, inc. I da CF/88), bem como um dos elementos constitutivos do Estado. A soberania é "a capacidade de o Estado ser reconhecido como pessoa jurídica de direito público para a comunidade internacional" (FIGUEIREDO, 2014, p. 97).

Por conseguinte, tem-se a propriedade privada (inc. II) e a função social da propriedade (inc. III), como princípios orientadores da Ordem Econômica. Todavia, seus fundamentos estão expressos no rol dos direitos e garantias individuais que constituem cláusulas pétreas do Estado brasileiro.

O direito à propriedade constitui garantia real que permite ao agente usar, gozar ou mesmo dispor de um bem, tendo exclusividade. A propriedade privada, assim, vertida sob a ótica de princípio da ordem econômica, se insere no processo de produção, envolvendo a propriedade dita dinâmica - dos bens de consumo e produção (ARAÚJO; NUNES JÚNIOR, 2006, p. 467).

Por outro lado, a função social da propriedade implica uma finalidade social - salvaguardada pelo Constituinte de 1988 - buscando impedir que o particular utilize a propriedade de modo desviado, prejudicando o meio social. Destarte, fundamenta-se conforme os parâmetros da justiça social. Figueiredo (2014, p. 99) declara:

Assim, a função social da propriedade cuida da socialização desses direitos individuais, de cunho privatista, na qual o uso e a fruição da propriedade privada passam a ser condicionados ao atendimento de um objetivo maior, previamente estipulado em lei, cuja inobservância legitima a interferência do Estado sob a esfera de domínio privado do proprietário, podendo acarretar, inclusive, a expropriação do bem. 
Ademais, posteriormente, temos a livre concorrência como princípio geral da atividade econômica (art. 170, inc. IV). Araújo e Nunes Junior (2006, p. 469) defendem que seu escopo é fundar um mercado ideal, caracterizado pelo assim chamado "estado de concorrência". Figueiredo (2014, p. 102), por sua vez, aduz que este é um dos fundamentos da economia liberal, sendo corolário da livre iniciativa.

Nessa seara, a doutrina majoritária tem defendido que o princípio da livre concorrência reporta-se a um desdobre do fundamento da livre iniciativa. Tal princípio tem por fim garantir o acesso e permanência de competidores na atividade mercantil, conferindo ao Estado a possibilidade de intervir na iniciativa dos agentes econômicos quando verificar a dominação do mercado por alguns desses agentes.

Conforme Tavares $(2006$, p.83) o princípio da livre concorrência possibilita a abertura jurídica aos particulares para competirem entre si. Todavia, devem observar a licitude do ato, objetivando o êxito econômico das leis de mercado e a contribuição para o desenvolvimento nacional e a justiça social.

Posteriormente, temos os princípios da defesa do consumidor (inc. V), a defesa do meio ambiente (inc. VI), a redução das desigualdades regionais e sociais (inc. VII) e a busca pelo pleno emprego (inc. VIII) como integrantes dessa ordem econômica dinâmica fundada na existência digna da pessoa humana. Finalmente, o constituinte de 1988 acautelou tratamento favorecido para as empresas de pequeno porte (inc. IX). Nesse sentido, Figueiredo (2014, p. 104) preleciona:

Com o avanço da globalização e das grandes empresas de capital transnacional, as técnicas de produção em massa passam por processos de mecanização e informatização exigindo muito menos quantidade de mão de obra, primando pela especialização de um número cada vez menor de trabalhadores para realização de suas atividades. A inovação tecnológica permitiu que tais atividades econômicas passassem a ser desenvolvidas por um número cada vez maior de empresas de médio e pequeno porte, detentoras do know-how de produção, aumentando a concorrência do mercado, em que pese não deterem poderio, nem capital econômico de grande porte. Daí a importância das empresas de médio e pequeno porte no atual mercado, como entidades concorrenciais, empregadoras e geradoras de renda.

Assim, faz-se necessário trazer à baila que o favorecimento aqui conferido não contraria a fundamentação da livre iniciativa e o princípio da defesa da concorrência, mas salvaguarda em termos concorrenciais as entidades de pequeno porte que não têm condições de competir de forma direta com empresas de grande porte.

\section{INFRAÇÕES À ORDEM ECONÔMICA E A ATUAÇÃO DO CADE (CONSELHO ADMINISTRATIVO DE DEFESA ECONÔMICA)}

A defesa da concorrência tem como finalidade precípua combater atos ilegais, com o 
objetivo de fraudar a procura e a oferta, consistindo essas práticas em abuso de poder ou atos de deslealdade (MASSO, 2016, p. 151). "Enquanto no primeiro caso se tutelam as estruturas de mercado competitivas e eficientes, no segundo caso o que se tutela é a lealdade dos concorrentes no desenvolvimento de atividade econômica" (MASSO, 2016, p. 156).

Segundo Figueiredo (2014, p. 269), a conduta de abusar do poder econômico é "todo ato de agente econômico que, valendo-se de sua condição de superioridade econômica, atua prejudicando a concorrência, o funcionamento do mercado ou, ainda, aumentando arbitrariamente seus lucros".

"Desse modo, ultimamente a aplicação da vigente Lei de proteção da concorrência contra o abuso do poder econômico, chamada de antitruste (Lei $\mathrm{n}^{\circ} 12.529 / 2011$ ), e da lei que tutela as práticas leais de competição, chamada de Lei de propriedade industrial (Lei n 9.279/1996)" (MASSO, 2016, p. 156). Considerando como bem tutelado na infração do abuso do poder econômico, a sistemática de mercado, contudo, influencia em todo o conjunto de princípios da ordem econômica (MASSO, 2016, p. 160).

A Lei Antitruste enumera no seu art. 31, como sujeito ativo dos delitos econômicos: as pessoas físicas, jurídicas de direito público ou privado, quaisquer associações de entidades ou pessoas, constituídas de fato ou de direito, com ou sem personalidade jurídica. A responsabilidade é objetiva (ou seja, independente da demonstração de culpa), bem como solidária entre a empresa e seus agentes. Caracteriza o art. 36, da citada Lei, como núcleo do tipo de modo exemplificativo, as seguintes condutas:

I - limitar, falsear ou de qualquer forma prejudicar a livre concorrência ou a livre iniciativa;

II - dominar mercado relevante de bens ou serviços;

III - aumentar arbitrariamente os lucros; e

IV - exercer de forma abusiva posição dominante. (Grifos nossos)

A Constituição Federal de 1988 , no seu art. $173, \S^{\circ}$, expressa como abuso do poder econômico todo ato de dominação do mercado que vise à eliminação da concorrência e ao aumento injusto dos lucros. Tendo como consequência nesses casos, de acordo com a Lei de Proteção à Concorrência, a desconsideração da personalidade jurídica, também trazida pelo art. 50 do Código Civil brasileiro. A desconsideração da personalidade jurídica tem como penalidade aos seus sócios responder ilimitadamente e diretamente, deixando de haver o princípio da autonomia patrimonial das pessoas jurídicas. Assim entendendo os Tribunais Superiores sobre o tema:

CIVILE PROCESSUALCIVIL. DECISÃODEINDEFERIMENTODOPEDIDO DE DESCONSIDERAÇÃO DA PERSONALIDADE JURÍDICA. AGRAVO DE INSTRUMENTO. VERIFICAÇÃO DE ABUSO DE PERSONALIDADE JURÍDICA DA EMPRESA. OCULTAÇÃO DO PATRIMÔNIO PARA EVITAR A CONSTRIÇÃO DECORRENTE DAS EXECUÇÕES DOS CREDORES. CUMPRIMENTO DE SENTENÇA QUE SE PROCESSA POR MAIS DE DEZ ANOS. INDÍCIOS DE CONFUSÃO PATRIMONIAL. APROPRIAÇÃO DOS PROVEITOS ECONÔMICOS DA EMPRESA PELOS SÓCIOS. AUSÊNCIA 
DE QUALQUER ATIVO QUE POSSA SALDAR O VALOR DECORRENTE DE SENTENÇA TRANSITADA EM JULGADO. PROVIDÊNCIA PREVISTA NO ART. 50 DO CÓDIGO CIVIL QUE SE MOSTRA ADEQUADA AO CASO CONCRETO. PROCEDIMENTO QUE DEVERÁ OBSERVAR A SISTEMÁTICA DO NOVO CÓDIGO DE PROCESSO CIVIL. CONHECIMENTO E PROVIMENTO DO AGRAVO DE INSTRUMENTO. 1. O Superior Tribunal de Justiça possui iterativa jurisprudência no sentido de que a desconsideração da personalidade jurídica é medida excepcional, devendo ser observada a autonomia patrimonial da pessoa jurídica, enquanto não concorrer abuso da personalidade jurídica, desvio de finalidade ou confusão patrimonial por parte dos sócios. 2 . A execução não deve restar frustada diante dos indícios de abuso da personalidade jurídica da empresa agravada, devendo-se possibilitar que o crédito do exequente seja saldado após a medida extrema da desconsideração da personalidade jurídica, que deverá observar o procedimento vigente, na sistemática do Novo Código Civil, com o devido processamento do incidente e possibilitando ao agravado o exercício do contraditório e da ampla defesa. 3. Precedentes do STJ (EREsp 1306553/SC, Rel. Ministra Maria Isabel Gallotti, Segunda Seção, julgado em 10/12/2014, DJe 12/12/2014; AgRg no AREsp 621.926/RJ, Rel. Ministro Marco Aurélio Bellizze, Terceira Turma, julgado em 12/05/2015, DJe 20/05/2015; AgRg no AREsp 402.622/RJ, Rel. Ministro Marco Buzzi, Quarta Turma, julgado em 05/05/2015, DJe 12/05/2015) 4. Agravo de instrumento conhecido e provido. (TJ-RN - AI: $20160032673 \mathrm{RN}$, Relator: Desembargador Virgílio Macêdo Jr., Data de Julgamento: 09/05/2017, $2^{\mathrm{a}}$ Câmara Cível) (grifo nosso) (RIO GRANDE DO NORTE, 2017)

Portanto, são consideradas como condutas abusivas a venda casada, a formação de cartel, os sistemas seletivos de distribuição e preços predatórios (FIGUEIREDO, 2014, p. 280). Já a concorrência desleal é qualquer ato que atinja outro concorrente, independentemente do poder econômico, sendo importante a lesão. "As ações criminais são privadas e deverão ser promovidas por intermédio de queixa-crime lesão" (MASSO, 2016, p. 226). Nesse caso, é a Lei de propriedade industrial que tipifica o núcleo desse tipo, estando elas expostas no art. 195:

I - publica, por qualquer meio, falsa afirmação, em detrimento de concorrente, com o fim de obter vantagem;

II - presta ou divulga, acerca de concorrente, falsa informação, com o fim de obter vantagem;

III - emprega meio fraudulento, para desviar, em proveito próprio ou alheio, clientela de outrem;

IV - usa expressão ou sinal de propaganda alheios, ou os imita, de modo a criar confusão entre os produtos ou estabelecimentos;

$\mathrm{V}$ - usa, indevidamente, nome comercial, título de estabelecimento ou insígnia alheios ou vende, expõe ou oferece à venda ou tem em estoque produto com essas referências;

VI - substitui, pelo seu próprio nome ou razão social, em produto de outrem, o nome ou razão social deste, sem o seu consentimento;

VII - atribui-se, como meio de propaganda, recompensa ou distinção que não obteve;

VIII - vende ou expõe ou oferece à venda, em recipiente ou invólucro de outrem, 
produto adulterado ou falsificado, ou dele se utiliza para negociar com produto da mesma espécie, embora não adulterado ou falsificado, se o fato não constitui crime mais grave;

IX - dá ou promete dinheiro ou outra utilidade a empregado de concorrente, para que o empregado, faltando ao dever do emprego, lhe proporcione vantagem;

$X$ - recebe dinheiro ou outra utilidade, ou aceita promessa de paga ou recompensa, para, faltando ao dever de empregado, proporcionar vantagem a concorrente do empregador;

XI - divulga, explora ou utiliza-se, sem autorização, de conhecimentos, informações ou dados confidenciais, utilizáveis na indústria, comércio ou prestação de serviços, excluídos aqueles que sejam de conhecimento público ou que sejam evidentes para um técnico no assunto, a que teve acesso mediante relação contratual ou empregatícia, mesmo após o término do contrato;

XII - divulga, explora ou utiliza-se, sem autorização, de conhecimentos ou informações a que se refere o inciso anterior, obtidos por meios ilícitos ou a que teve acesso mediante fraude; ou

XIII - vende, expõe ou oferece à venda produto, declarando ser objeto de patente depositada, ou concedida, ou de desenho industrial registrado, que não o seja, ou menciona-o, em anúncio ou papel comercial, como depositado ou patenteado, ou registrado, sem o ser;

XIV - divulga, explora ou utiliza-se, sem autorização, de resultados de testes ou outros dados não divulgados, cuja elaboração envolva esforço considerável e que tenham sido apresentados a entidades governamentais como condição para aprovar a comercialização de produtos.

Pena - detenção, de 3 (três) meses a 1 (um) ano, ou multa. (Grifos nossos)

Por fim, o Conselho Administrativo de Defesa Econômica (CADE) exerce poder de polícia, atuando na fiscalização e aplicação de sanções decorrentes de ilícitos administrativos cometidos na ordem econômica (FIGUEIREDO, 2014, p. 280). O CADE é um dos órgãos da composição do SBDC, com jurisdição em todo o território nacional, e vinculado ao Ministério da Justiça, tendo natureza de autarquia federal. Sendo seus órgãos, a atuação do Ministério Público Federal, seus recursos e competência de cada órgão delimitados pela Lei 12. 529/2011.

As penalidades impostas pelo CADE podem ser de naturezas ordinárias (art. 37 da Lei 12.529/2011) são as "aquelas, por sua vez, podem ser aplicadas de forma única ou diária"; a extraordinária, prevista no artigo 38, desta forma, se observa que podem ser aplicadas cumulativamente. (FIGUEIREDO, 2014, p. 281). Logo, conclui-se que o sistema da ordem econômica é bem estruturado, o que falta é fiscalização para coibir tais condutas nocivas.

\section{A IDEIA DE NEUTRALIDADE TRIBUTÁRIA COMO GARANTIA DA CONCORRÊNCIA}

A sistemática constitucional de 1988 prevê um aparato de direitos, em busca de concretizar o bem-estar e a paz social. Diante disso, a tributação interfere na ordem econômica, uma vez do 
dever fundamental de pagar impostos por parte dos cidadãos, que ocorre o seu financiamento. Nabais (2005, p. 13), afirma que "o estado fiscal é assim, um estado limitado no que ao domínio económico concerne". Desse modo, haveria uma relação sinalagmática de influências entre o ente estatal e a economia.

Porém, a tributação não pode ser demasiadamente concebida, mas pautar-se nos princípios da capacidade contributiva, igualdade, legalidade e tipicidade, para que não venha distorcer o sistema tributário e desvincular-se da teoria da tributação adotada pelo ordenamento jurídico brasileiro.

"Desde meados do século XX, a doutrina e a jurisprudência perceberam a importância do direito tributário no exercício de uma função interventiva na direção econômica e social, para além de sua tradicional função arrecadadora" (BONFIM, 2011, p. 14.)

Devido à interdisciplinaridade existente entre o direito econômico e o tributário, o princípio funcional da ordem econômica tornou-se imprescindível para analisar o cumprimento dos objetivos tributários. São esses princípios funcionais, a livre inciativa, livre concorrência, mercado livre e abuso do poder econômico (BONFIM, 2011, p. 14).

Assim como a tributação constitui a maior ferramenta do Estado na intervenção do mercado, como forma de reprimir os abusos econômicos e afastar condutas que obstem ao cumprimento dos ditames da ordem econômica (VIDIGAL, 2015, p.172).

Por conseguinte, em busca de evitar distorções no mercado, decorrentes dos tributos, o legislador adotou três espécies de normas: as indutoras, as simplificadoras, as arrecadadoras e simplificadoras. As indutoras, como é o caso da função extrafiscal de alguns tributos, estimula ou desestimula comportamentos. As normas arrecadadoras criam casos de isenção ou de não incidência em determinadas situações. E por último, as normas simplificadas, como o próprio nome já diz, tornam mais fácil o recolhimento, por razões socioeconômicas. Portanto, percebese que esses tipos de normas podem cumular-se, por exemplo, uma mesma norma ser indutora e simplificada (BONFIM, 2011, p. 15).

Por essas razões, conclui-se que as normas indutoras são claramente norteadas pelo princípio da livre concorrência, ao mesmo tempo que em uma via de mão dupla, os tributos na dosagem certa favorecem o equilíbrio concorrencial, evitando lucros exorbitantes (BONFIM, 2011, p. 197).

Para isso, a abordagem da neutralidade tributária, atua de acordo com a função adotada pela tributação. Se trata de um tributo fiscal, a concorrência mantém-se neutra. Se extrafiscal, logo indutora, o princípio da concorrência atuará e impossibilitará uma neutralidade tributária (BONFIM, 2011, p. 198).

Desta forma, a neutralidade tributária quando adotada em tributos com finalidade fiscal, constitui uma das formas de concretização do princípio da concorrência, ajudando a evitar distorções de preços no mercado, maximizando o poder de compra dos consumidores e atraindo investidores para o Brasil (FARO; ROCHA, 2017).

Contudo, o que conceitua neutralidade tributária? Resumidamente, é o dever do Estado de ser imparcial em situações que causem equilíbrio à concorrência, levando igualdade ao sistema 
concorrencial (LIMA, 2005, p. 61). De um modo mais completo, nas palavras de Lima (2005, p. 73):

A neutralidade tributária, desse modo, pode ser entendida, em primeiro plano, como um dever negativo, ou de omissão ao Estado, de não interferir na concorrência por meio da tributação, e, em segundo plano, como um dever positivo ou de ação, de prevenir ou restaurar, quando for o caso, a igualdade de condições na concorrência, quando esta se encontre ameaçada por ações de particulares ou outros fatores relevantes, sempre objetivando a preservação da igualdade de condições competitivas no mercado.

Verificando a necessidade dessa situação no ordenamento jurídico brasileiro, a Emenda Constitucional 42/2003, introduziu o artigo 146-A, que assim dispõe: "lei complementar poderá estabelecer critérios especiais de tributação, com o objetivo de prevenir desequilíbrios da concorrência, sem prejuízo da competência de a União, por lei, estabelecer normas de igual objetivo". Lima (2005, p. 76) argumenta que a inclusão do presente artigo na Constituição inaugurou o princípio da neutralidade tributária que deve orientar todo o complexo tributário.

Alhures há autores, como por exemplo, Caliendo (2011, p.119-121; 123-124) que discordam desse pensamento, por entender que a neutralidade tributária é uma questão ultrapassada, que não carece de sentido no ordenamento jurídico brasileiro, porque foi superado pelo princípio da concorrência, e este sim, é o ponto de equilíbrio entre o Sistema Tributário e a Ordem Econômica e Financeira. Uma vez que a neutralidade tributária é entendida como uma mínima atuação do Estado no mercado e isso geraria uma ineficiência no sistema econômico, além de que não corresponderia aos ideais propostos pela Constituição de 1988 (CALIENDO, 2011, p. 125).

Como a neutralidade representaria uma inércia do Estado, seria a negação de todo o sistema constitucional, tendo em vista que seu próprio texto prever extrafiscalidade e métodos de combate as distorções de mercado (SILVA, 2017, p.27-28)

Entretanto, não se trata do entendimento expresso nesse artigo, como argumenta (SILVA, 2017, p.29):

Ao que pese a função instrumental da tributação ressaltada pelo artigo 146A da Constituição tal instrumentalidade derivada desse artigo não implica à possibilidade de utilização dos tributos como meio de corrigir falhas concorrenciais estruturais, mas sim apenas aquelas decorrentes do próprio poder de tributar, sob pena de distorção ou sobreposição de funções ao que tange o papel do Sistema Brasileiro de Defesa da Concorrência.

A neutralidade tributária, quando aplicada no combate às práticas de tributação que geram concorrência desleal fortalecem ainda mais o princípio da concorrência. Caliendo (2011, p.127), discorrendo sobre a neutralidade fiscal sobre o consumo afirma:

Não podemos afirmar que existe um modelo geral de neutralidade, mas podemos corroborar a afirmação de que a tributação deve evitar gerar ineficiências no sistema, melhor dizendo, é vedado constitucionalmente, toda ação econômica que vise falsear, limitar ou prejudicar a livre concorrência de mercado. 
Ávila (2015, p. 103), sustenta que "a neutralidade representa uma manifestação estipulada da própria igualdade na sua conexão com o princípio da liberdade de concorrência”. Para o autor, a neutralidade e igualdade não se diferenciam, consistindo apenas perspectiva daquela no que tange ao aspecto subjetivo e temporal.

Portanto, conforme já foi exposto, a tributação possui influência no mercado, inclusive o legislador veio a reconhecer isso através da inclusão do art. 146-A, para isso é preciso que o Estado se abstenha de realizar práticas nocivas a concorrência, abusando do seu poder e interferindo na negativamente na economia.

\section{RESPONSABILIDADE SOCIAL DAS EMPRESAS COMO FORMA DE FAVORECER A DEFESA DA CONCORRÊNCIA}

O contexto histórico no qual surge a busca pela Responsabilidade Social das Empresas transcende, a partir dos movimentos trabalhistas, a Revolução Industrial, a Constituição do México de 1917, eclodindo nos textos de Milton Friedman de 1962, que trouxeram, pela primeira vez, o tema. No entanto, a teoria do acionista, trazida por ele, entendia que a empresa seria socialmente responsável, se cumprisse o que estava na lei, concretizando seu objetivo, que seria gerar lucros, devendo o Estado, conforme os pensamentos de Adam Smith na sua obra Capitalismo e Liberdade, não regular o mercado, pois ele de forma livre acabaria por promover o bem-estar coletivo (BARBIERI; CAJAZEIRA, 2012, p. 12).

Com o passar dos anos, diversas outras teorias surgiram com objetivo de combater e trazer mais novos bens jurídicos a serem tutelados. Por exemplo, a teoria das partes interessadas, que inclui a tutela do meio ambiente. Por fim, a teoria do contrato social, a partir do a pacto que o povo decidiu submeter-se, deve a ele ser assegurado um conjunto de direitos, como a preocupação com as futuras gerações, da mesma maneira a perspectiva de justiça social, buscando diminuir as desigualdades sociais (BARBIERI; CAJAZEIRA, 2012, p. 10; 24; 39; 41).

Diante disso, Carrol, conceitua a responsabilidade social das empresas pela compreensão das "expectativas econômicas, legais, éticas, discricionárias que a sociedade tem em relação às organizações em dado período. Posteriormente, Carrol substitui a palavra discricionárias por filantrópicas" (BARBIERI; CAJAZEIRA, 2012, p. 53).

A responsabilidade social das empresas está intimamente incluída no ordenamento jurídico brasileiro, através do princípio da função social da propriedade, decorrendo deste, o princípio da função social da empresa, além de está fundamentada em outro supraprincípio como a dignidade da pessoa humana. Nessa seara, Grau (2010, p. 101) preleciona que:

A Constituição do Brasil de 1988 projeta um Estado desenvolto e forte, o quão necessário seja para que os fundamentos afirmados no seu art. $1^{\circ}$ e os dispositivos definidos no art. $3^{\circ}$ venham a ser plenamente realizados, garantindo-se tenha por fim, a ordem econômica, assegurar a todos existência digna. 
A função social da empresa argumenta que o papel da companhia representa não apenas alcançar lucros, fornecer empregos e ofertar bens e serviços, mas ainda, ela detém um fim social, um intuito maior, qual seja o de, em conjunto com o Estado, e observando as leis, os princípios éticos e morais, colaborar com o desenvolvimento da sociedade, do meio ambiente, e com o próprio país em que ela exerce suas atividades. "Concluindo, a responsabilidade social empresarial total impõe o cumprimento simultâneo das responsabilidades econômicas, legais, éticas e filantrópicas" (BARBIERI; CAJAZEIRA, 2012, p. 55).

Desta forma, um dos ideais trazidos por tal conceito, é o cumprimento dos princípios da ordem econômica, constituindo a responsabilidade social das empresas uma forte aliada para a defesa da concorrência, fazendo repensar um novo paradigma que as companhias devem seguir.

\section{CONSIDERAÇÕES FINAIS}

Em vista de tecer a linha histórica da ordem econômica nas Constituições brasileiras, chegaram-se as seguintes conclusões: que ela é frutos das transformações histórico-sociais. A primeira Constituição a tratar sobre o tema foi a 1934, influenciada por movimentos sociais, da Constituição do México de 1917e a de Weimar de 1919. Na de 1937, a ordem econômica passou a ter um capítulo próprio, que antes não possuía, enquanto que a de 1946 trouxe nela os ideais de justiça social, liberdade de iniciativa e a dignidade do trabalho humano, buscando equilibrar a balança mercantilista. No entanto, com a de 1967, com a ditadura militar, teve um perfil mais desenvolvimentista. Enquanto que a Emenda Constitucional de 1969 veio reafirmando as conquistas jurídicas pretéritas. Por fim, a de 1988, fundamentou na valorização do trabalho, da livre iniciativa, com vistas a assegurar uma existência digna e pautada nos ditames da justiça social.

Diante da atual ordem econômica, as principais normas que a salvaguardam, é conforme a doutrina majoritária, pautada no sistema capitalista, em razão de privilegiar o direito de propriedade, a livre iniciativa, a livre concorrência e a soberania nacional. Por outro lado, com o objetivo de contrapor esses ideais e trazer um Estado do bem-estar social, preocupou-se com a função social da propriedade, a defesa do consumidor, a redução das desigualdades sociais e regionais, a busca do pleno emprego e tratamento favorecido as empresas de pequeno porte. Buscando assim, proteger o bem comum.

Com a finalidade de combater as infrações à ordem econômica, reprimindo condutas abusivas e desleais, o Estado intervém na economia, materializando-se na Lei $\mathrm{n}^{\circ} 12.529 / 2011$ (antitruste) e a Lei $n^{\circ}$ 9.279/1996 (propriedade industrial). A Lei antitruste, no seu art. 36, traz condutas que correspondem a uma responsabilidade objetiva para as pessoas físicas e jurídicas que realizem essas condutas danosas, para o mercado e a concretização dos ditames sociais. Dessa maneira, tendo por intuito enfrentar ainda mais essas condutas, trouxe a previsão no art. 50 do 
Código Civil e art. 133 do Código de Processo Civil de 2015, o incidente de desconsideração da personalidade jurídica. Bem como, também foi criado um Conselho Administrativo de Defesa Econômica (CADE) para exercer o poder de polícia diante de condutas nocivas a mercancia.

Entretanto, não tem sido suficiente para reprimir de forma eficaz essas infrações à ordem econômica, principalmente aquelas induzidas pelo ente estatal através da tributação. Assim sendo, examinou a neutralidade tributária e responsabilidade social das empresas como instrumentos para a defesa da concorrência.

Devido a isso, entende-se que a neutralidade tributária é um mecanismo para diminuir as condutas lesivas, uma vez que muitos dos participantes ativos utilizam mecanismos ilícitos para consegui-la, por outro lado ajuda a concretizar os princípios da capacidade contributiva, isonomia e justiça social. Porém, não pode ser adotada de forma desenfreada, devido à sistemática constitucional e ao dever fundamental de pagar impostos, para a concretização de outros direitos e do financiamento do Estado.

Por outro lado, a responsabilidade social das empresas entraria em cena para retornar os conceitos éticos que o direito não alcança somente com a norma. Possibilitando o retorno da discussão sobre o direito estaria realmente dissociado da moral e da ética, ou se seriam imprescindíveis suas ferramentas para a execução do "espírito das leis". Funciona, nesse liame, como ferramenta importantíssima para a adoção de práticas empresariais cooperantes a livre concorrência de mercado.

\section{REFERÊNCIAS}

ARAÚJO, Luiz Alberto David; NUNES JÚNIOR, Vidal Serrano. Curso de direito constitucional. 10. ed. São Paulo: Saraiva, 2006.

ÁVILA, Humberto. Teoria da igualdade tributária. 3. ed. São Paulo: Malheiros, 2015.

BARBIERI, José C.; CAJAZEIRA, Jorge E. R. Responsabilidade social empresarial e empresa sustentável. São Paulo: Saraiva, 2012.

BONFIM, Diego. Tributação e livre concorrência. São Paulo: Saraiva, 2011.

CALIENDO, Paulo. Princípio da livre concorrência em matéria tributária: conceito e aplicação. Revista da FESDT, Porto Alegre, n. 7, p. 115-132, jan/jun, 2011.

DALLARI, Dalmo de Abreu. Elementos de teoria geral do estado. 19. ed. São Paulo: Saraiva, 1995.

FARO, Maurício P.; ROCHA, André S. Neutralidade tributária para consolidar a concorrência. Disponível em: http://www.conjur.com.br/2012-ago-21/neutralidade-tributariafator-fundamental-livre-concorrencia. Acesso em: 15 maio 2017. 
FIGUEIREDO, Leonardo Vizeu. Lições de direito econômico. 7. ed. Rio de Janeiro: GEN, 2014.

GRAU, Eros Roberto. Ordem econômica na constituição de 1988: interpretação e crítica. São Paulo: Malheiros, 2010.

LIMA, Ricardo S. de Freitas. Livre concorrência e o dever de neutralidade. 2005. 143 f. Dissertação (Mestrado em direito) - Faculdade de Direito da Universidade do Rio Grande do Sul, Porto Alegre, 2005.

MASSO, Fabiano Del. Direito econômico esquematizado. 4. ed. São Paulo: Método, 2016.

NABAIS, José Casalta. A face oculta dos direitos fundamentais: os deveres e os custos dos direitos. Revista da AGU, v. 1, n. 01, 30 jun. 2005. Disponível em: https://seer.agu.gov.br/index. php/AGU/article/view/525 Acesso: 22 nov. 2021.

RIO GRANDE DO NORTE. Tribunal de Justiça. Agravo de instrumento com suspensividade: AI 20160032673 RN. Disponível em: https://tj-rn.jusbrasil.com.br/jurisprudencia/457566081/ agravo-de-instrumento-com-suspensividade-ai-20160032673-rn. Acesso em: 23 maio 2015.

SILVA, Amanda Albano Souza da. Os efeitos da tributação na ordem econômica: uma análise concorrencial. 2017. 57 f. Trabalho de Conclusão de Curso (Bacharelado em Direito) - Pontifícia Universidade Católica do Rio de Janeiro, 2017.

SILVA, José Afonso da. Curso de direito constitucional positivo. 19. ed. São Paulo: Malheiros Editores, 2001.

TAVARES, André Ramos. Direito constitucional econômico. 2. ed. São Paulo: Método, 2006.

VIDIGAL, Carlos Linek. Poder de tributar: seus efeitos sobre a concorrência. 2015. $184 \mathrm{f}$. Dissertação (Mestrado em Direito) - Faculdade de Direito da Universidade de São Paulo, São Paulo, 2015.

Como citar: BRISOLA, Anna Karla da Silva; ALVES JUNIOR, José da Silva; BARACHO, Hertha Urquiza. A neutralidade tributária e a responsabilidade social das empresas como contributos para o combate às infrações à ordem econômica. Revista do Direito Público, Londrina, v. 16, n. 3, p. 44-59, dez. 2021. DOI: 10.5433/24157-108104-1.2021v16n3p.44. ISSN: 1980-511X

Recebido em: 20/12/2018

Aprovado em: 03/08/2020 